\title{
FV-RES ile Beslenen Anahtarlamalı Relüktans Motorun Analizi
}

\author{
Dilan DEMIR AKTAŞ ${ }^{1}$, Serhat Berat EFE ${ }^{2 *}$ \\ ${ }^{I}$ Bitlis Eren Üniversitesi, Fen Bilimleri Enstitüsü, Bitlis \\ ${ }^{2}$ Bandırma Onyedi Eylül Üniversitesi, Elektrik Mühendisliği Bölümü, Bandırma \\ (ORCID: 0000-0002-0185-6375) (ORCID: 0000-0001-6076-4166)
}

\begin{abstract}
$\ddot{\mathbf{O} z}$
Son yıllarda yenilenebilir enerji kaynakları üzerine yapılan çalışmaların artış göstermesi; birçok alanda olduğu gibi endüstriyel ve makine sanayiinde de tercih edilmesine neden olmaktadır. Motor sürücüleri teknolojisindeki gelişmelerle birlikte, klasik elektrik makinelerine alternatif olarak düşünülen Anahtarlamalı Relüktans Motor(ARM)lar, aynı güçteki klasik makinelerden daha ucuz ve basit yapılı olmasından ötürü daha avantajlı hale gelmiş̧ir. Bu çalışmada bir fotovoltaik (FV) sistem ve rüzgâr enerjisi sistemi (RES) ile oluşturulan hibrit bir enerji üretim sistemi tarafindan beslenen ARM'nin, depolama üniteli ve depolama ünitesi olmadan doğrudan beslenme durumundaki performans analizi yapılmıştır. Analiz sisteminin fiziksel olarak kurulumunun yapılmasının ardından motorun depolama ünitesinden beslenme durumundaki davranışı belirlenmiştir. Daha sonra, bu çalışmanın temel amacı kapsamında, motor, hibrit sistemden doğrudan beslenmiş ve çeşitli yük durumlarına göre ARM'nin çalışma performansı gözlenmiştir. Kurulan bu sistem, endüstriyel sanayide ve tarımsal sulamada tercih edilmesi durumunda alınacak verim ve motorun potansiyeli açısından incelenmiş, elde edilen sonuçlar sistem grafikleri üzerinden yorumlanarak planlama ve sistem mühendisleri için öneriler sunulmuştur.
\end{abstract}

Anahtar kelimeler: Anahtarlamalı Relüktans Motor, Yenilenebilir Enerji Kaynakları, Fotovoltaik Sistem, Rüzgâr Enerjisi Sistemi.

\section{Analysis of Switched Reluctance Motor Fed by PV-WES}

\begin{abstract}
As the studies on renewable energy sources are increased in recent years, such systems are preferred in many areas like industrial and machine industry. The Switched Reluctance Motor (SRM), which is considered as an alternative to conventional electric machines, has become more advantageous with the developments in motor-drive technology, because it is cheaper and simpler than the conventional machines of the same power. In this study, performance analysis of a SRM which was fed by a hybrid system that consist of photovoltaic (PV) system and wind energy system (WES), was performed with and without storage unit conditions. The behavior of the SRM with storage unit was determined after physical installation of analysis system. Then, as the main purpose of this study, the motor was fed directly from the hybrid system and the operating performance of SRM was observed according to the various load cases. Installed system was investigated in terms of efficiency and motor performance if preferred in industry and agricultural irrigation, results were reviewed by using obtained system graphs suggestions were presented for planning and system engineers.
\end{abstract}

Keywords: Switched Reluctance Motor, Renewable Energy Sources, Photovoltaic System, Wind Energy System.

\section{Giriş}

Konvansiyonel enerji kaynak rezervlerinin azalması, hızlı sanayileşme ve kentleşmeye bağlı olarak enerji ihtiyacının artması, enerji fiyatlarındaki artış ve buna bağlı olarak gelecekteki üretim tüketim dengesinin tehlikede olması, yenilenebilir enerji kaynaklarına yönelimi zorunlu hale getirmiştir. Özellikle fosil yakıt kullanımına bağlı sera etkisinin artması, küresel ısınma, hammadde fiyatlarındaki

*Sorumlu yazar: sefe@bandirma.edu.tr

Geliş Tarihi: 07.02.2019, Kabul Tarihi: 28.05.2019 
artış, çevre ve insan sağlı̆̆ı üzerindeki olumsuz etkileri, konvansiyonel enerji kaynak kullanımında bir takım zorlukların yaşanması yenilenebilir enerji kaynakları üzerine yapılan çalışmaların artan bir ivme göstermesinde etkili olmuştur. Ayrıca iletim ve dağıtım cihaz gereksinimini azaltması, yerel hizmet güvenini arttırması, son kullanıcının yakınına kurulabilmesi, çeşitli kontrol tekniklerinin kullanılması ile kurulu gücü düşük olan uygulamalar için verimli bir fotovoltaik sistem ve rüzgâr enerjisi sisteminden oluşan hibrit yapı oluşturmak daha avantajlı hale gelmiştir [1]. Bu sistemler elektriksel olarak paralel bağlanıp ve enerji şebekesi ile entegre edilip güç artırımı sağlanabilir [2-4]. Ulusal şebekeye bağlı ve ulusal şebekeden bağımsız olarak çalıştırılabilirler.

Yenilenebilir Enerji Kaynakları(YEK) üzerine yapılan çalışmaların artışıyla birlikte hibrit sistemler; makine ve sanayi uygulamalarında da tercih edilmeye başlanmıştır. Günümüzde öncelikli yüklerin hayati önem kazandığı sanayi bölgeleri için hibrit sistem çözümlerinin sağlayacağı katk1 çok önemlidir. Sanayide üretim sürekliliğinin sağlaması hayati önem taşımaktadır. Enerji kalitesi ve sürekliliği bu sektörün vazgeçilmez ana unsurlarıdır. Bu sürekliliğin hibrit sistemler ile sağlanabileceği elde edilen sonuçlar arasında en dikkat çekici sonuç olarak öne çıkmaktadır.

Son kırk yılda sürücü teknolojisindeki gelişmeler sayesinde klasik elektrik makinelerine alternatif olarak düşünülen Anahtarlamalı Relüktans Motorlar (ARM) diğer doğru akım (DA) motorlarına ve asenkron motorlara kıyasla yapısının basit, atalet momentinin düşük, imalatının ucuz olması ve yüksek hızlarda çalışabilmesi özelliklerinden dolayı makine sanayinde hızla yerini almıştır [5-7]. Yenilenebilir enerji kaynaklarıyla beslenen motor çalışmaları incelendiğinde ARM ile yapılan çalışmalar azımsanamayacak kadar çoktur [8-10]. Bu çalışmaların çoğu su pompalama sistemlerine odaklanırken, araştırmacılar motor yükleri olan sistemlerin kontrol tekniklerini ve performanslarını da araştırmışlardır [11]. 1960'lı yılların sonlarına kadar çok küçük güçlerde imal edilen ve üzerinde pek durulmayan ARM'ler, yarı iletken teknolojisindeki gelişmelere paralel olarak tekrar gündeme gelmiştir. 1970’li yıllarda ucuz ve hızlı elektronik güç anahtarlarının, anahtarlama döngülerini sağlayan yüksek performanslı mikroişlemcilerin ve yüksek güçlerde değişken relüktanslı motorların üretilmesi ile relüktans motorlar üzerine yapılan çalışmalar artmıştır ve günümüzde çeşitli alanlarda artarak devam etmektedir. [12-15].

\section{Materyal ve Metot}

Yenilenebilir enerji kaynakları ile konvansiyonel enerji üretim santrallerinin entegrasyonu sonucunda oluşturulan hibrit yapıların kullanımı, özel bölgelerin enerjilendirilmesinde kolayca uygulanabilmeleri, kaliteli ve kesintisiz enerji sağlayabildikleri için hızla yaygınlaşmaktadır. Güç sistemlerinde ana yüklerden biri motor yüklerdir. Motor parametrelerinin, gerilim ve akım gibi besleme parametrelerinden doğrudan etkilendiği bilindiğinden [16], bu çalışmada, Bitlis Eren Üniversitesi Rahva Yerleşkesi'nde kurulu olan ve FV sistem ile RES'ten oluşan hibrit enerji üretim sistemi tarafindan beslenen ARM'nin depolama üniteli ve depolama ünitesiz çalışması incelenmiştir. Bu sistemin bileşenleri izleyen bölümlerde detaylandırılmıştır.

\subsection{Anahtarlamalı Relüktans Motor(ARM)}

Mekanik olarak ARM oldukça basit yapıda bir elektrik makinasıdır. ARM'ler bir çeşit senkron motor olup ve rotorlarında sargı, mıknatıs ya da kısa devre halkası içermeyip saç paketinden oluşmaktadır. Bu motorların stator ve rotoru yüksek geçirgenlikli manyetik malzemeden yapılır [17]. ARM'nin bir faz eşdeğer devresi Şekil 1'de gösterilmiştir.

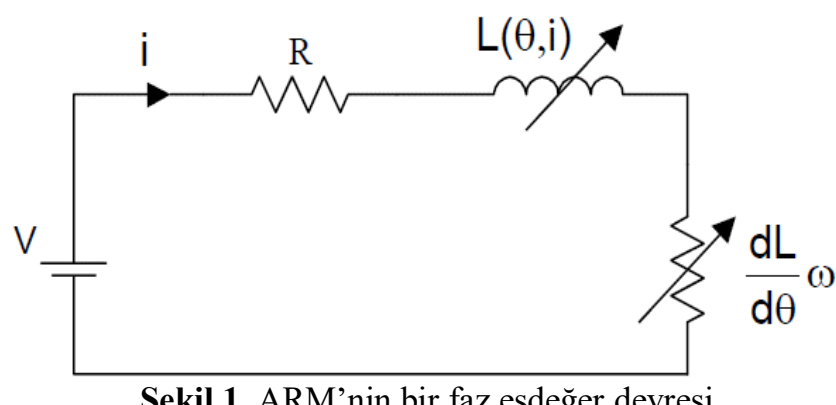

Şekil 1. ARM'nin bir faz eşdeğer devresi 
ARM'de bir faz için gerilim denklemi;

$V=R . i+\frac{\partial \phi(\theta, i)}{\partial t}-M(\theta) \frac{d i^{\prime}}{d t}$

şeklinde ifade edilmektedir. Burada V, DA kaynak gerilimi; R, stator sargı direnci; $\phi$, manyetik akı; i, faz akımı; $M(\theta)$, karşı1ıklı endüktans; $\theta$, rotor pozisyon açısı ve i',bir önce uyarılan sargı akımıdır [18]. Doyum ihmal edildiğinde manyetik akı endüktans parametresi cinsinden yazılabileceğinden (1) eşitliği

$$
V=R \cdot i+\frac{\partial L(\theta, i)}{\partial t}-M(\theta) \frac{d i^{\prime}}{d t}
$$

Şeklinde düzenlenebilir. Türevsel bileşen genişletildiğinde ve karşıllklı endüktans ihmal edildiğinde, $\omega$ açısal hız olmak üzere, (2) eşitliğinin son hali (3)’te verildiği gibi olacaktır,

$$
V=R . i+L(\theta) \frac{\partial i}{\partial \theta} \omega+i \frac{\partial L(\theta)}{\partial \theta} \omega
$$

Eşdeğer devreden görüleceği üzere, ARM'lar doğrudan DA ile çalışabilirler. Bu durum yenilenebilir enerji kaynakları ile birlikte kullanımlarında, özellikle FV sistem uygulamalarında büyük avantaj sağlamaktadır. Tasarlanan sitemde kullanılan ARM ve sürücü devresi Şekil 2'de gösterilmiştir.

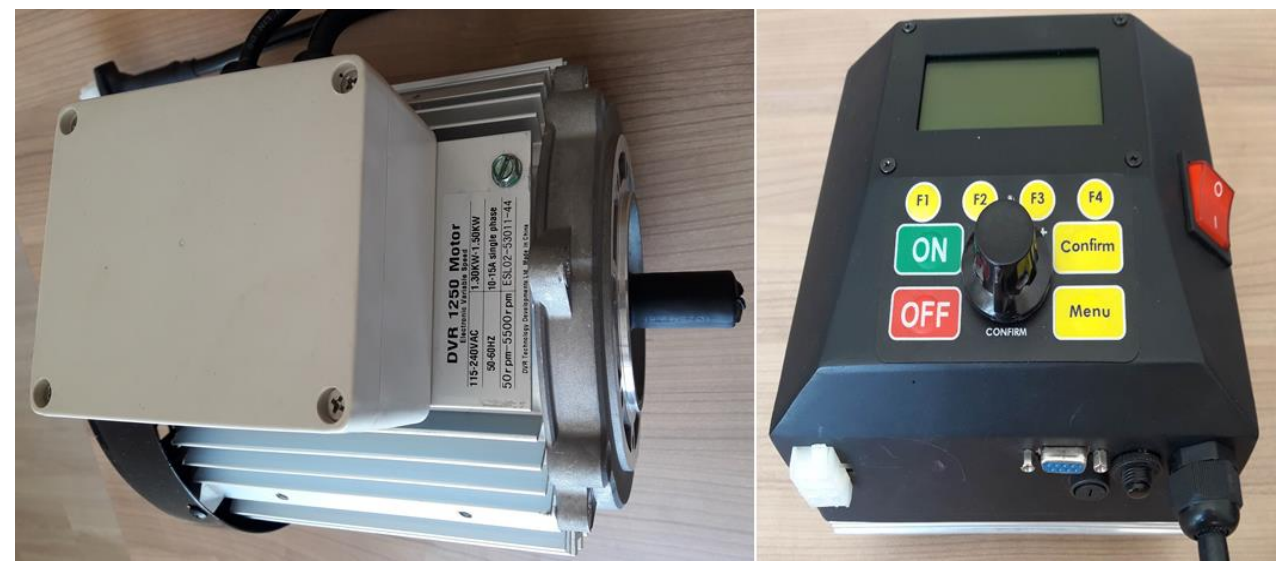

Şekil 2. ARM ve sürücü devresi

Şekilde verilen ARM'nin nominal çıkış gücü: $1.25 \mathrm{~kW}$, besleme gerilim-frekans aralı̆̆ı: $115 \mathrm{~V}$ $230 \mathrm{~V} / 50 \mathrm{~Hz}-60 \mathrm{~Hz}$, ve devir sayısı aralı̆̆ $50-5500$ (devir/dk) olarak tanımlanmaktadır.

\subsection{Fotovoltaik Sistemler}

Fotovoltaik (FV) modüller, güneş enerjisini doğrudan elektrik enerjisine dönüştürebilen alternatif enerji üretim araçlarıdır [19-20]. FV hücrelerin seri ve paralel bağlanmaları ile istenilen gerilim ve güç değerlerinde FV paneller, panellerin seri ve paralel bağlanması ile de FV sistemler elde edilir. Fotovoltaik hücreler yüzeylerine gelen güneş ışığını doğrudan elektrik enerjisine çeviren yarı iletken malzemelerden oluşmaktadır. Literatürde FV hücrelerin modellenmesi ile ilgili çok sayıda çalışma bulunmaktadır [21]. Bununla beraber, yapılan araştırmalar sonucunda elde edilen en yaklaşık model olarak tek diyotlu yapı ön plana çıkmaktadır [22]. Çoklu kristal yapıdaki tipik bir FV hücresinin tek diyotlu modeli Şekil 3'te gösterilmiştir. 


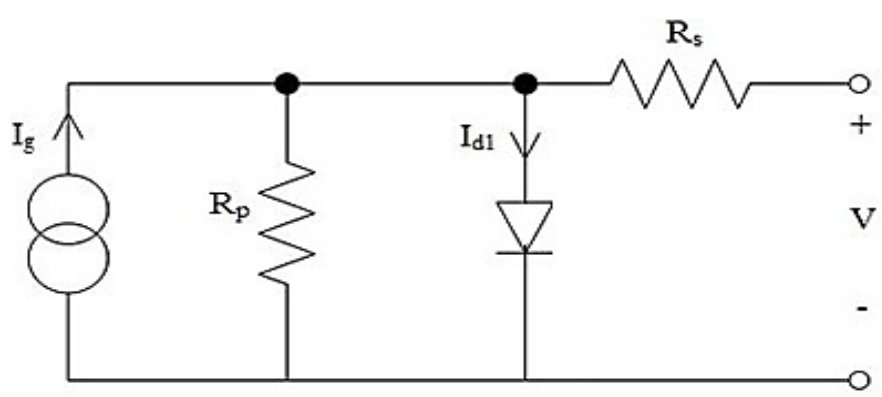

Şekil 3. Güneş pili eşdeğer DA akım modeli

Şekil 3'te verilen yapının matematiksel modeli denklem (4)'te verilmiştir.

$$
I_{F V}=I_{g}-I_{d 1}\left[e^{q\left(V+I R_{s}\right) / k T}-1\right]-\frac{V+I R_{s}}{R_{p}}
$$

Burada V; hücrenin uç gerilimi, IFv; çıkış akımı, k; Boltzmann sabiti, T; Kelvin cinsinden mutlak ortam sicaklığ1 ve q; elektron yüküdür [23].

FV panellerin enerji üretimini etkileyen en önemli faktörlerden biri panellere gelen güneş radyasyonu değeridir. Bitlis İline ait güneş radyasyonu haritası Şekil 4 'te verilmiştir [24].
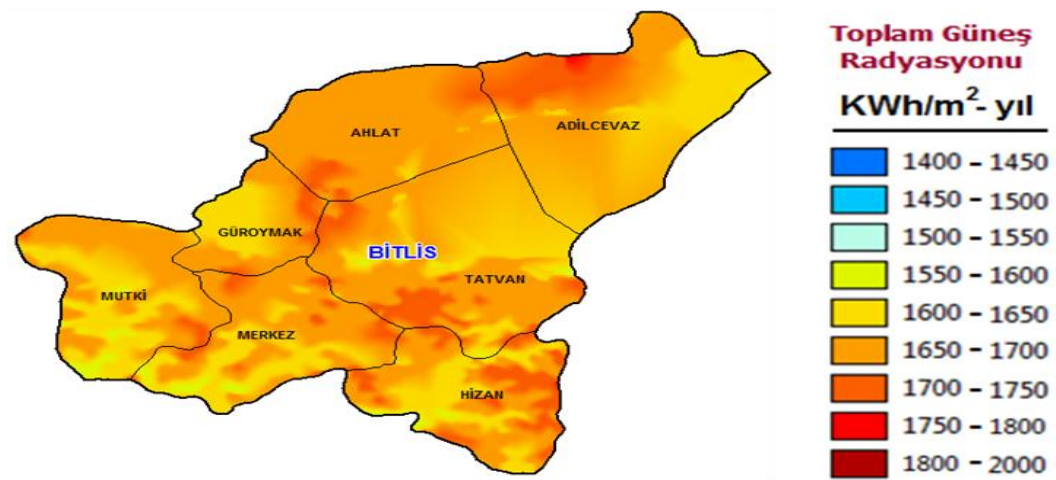

Şekil 4. Bitlis ili güneş enerjisi potansiyeli haritası

Şekilden görüleceği üzere Bitlis İli yüksek güneş radyasyonu değerine sahiptir. Bu durum güneş enerjisinden yüksek verim alınabileceğini göstermektedir.

Tasarlanan sistemin enerji üretim kaynaklarından olan FV sistem 6 adet panelden oluşmaktadır. FV panellerin her birinin maksimum gücü $150 \mathrm{~W}$, maksimum akımı $8.30 \mathrm{~A}$ maksimum gerilimi $18.04 \mathrm{~V}$, açık devre gerilimi $22.59 \mathrm{~V}$ ve kısa devre akımı 8.73A olarak verilmiştir. Sistemde kullanılan evirici ünitesi ise $3000 \mathrm{VA} / 2400 \mathrm{~W}$ anma gücünde $24 \mathrm{~V} \mathrm{DC}$ giriş / 230V, $50 \mathrm{~Hz}$ AC çıkış değerlerine sahiptir.

\subsection{Rüzgâr Enerjisi Sistemleri}

Rüzgâr enerjisi; kaynağı güneş olup, elektrik üretirken doğaya sera gazı ya da zararlı bir gaz salınımı olmayan, tamamen doğal, yenilenebilir ve sonsuz bir güçtür. Rüzgâr, güneşin yer yüzeyini farklı 1sıtmasından kaynaklanmaktadır. Bu sıcaklık ve basınç farkı hava hareketine neden olur. Rüzgâr enerjisi sistemleri tasarlanırken ilgili bölgedeki rüzgâr özelliklerine ihtiyaç duyulmaktadır. Ülkemizde bu bilgiler Yenilenebilir Enerji Genel Müdürlügü (YEGM) tarafından sağlanmaktadır. İlgili kurum tarafından yayınlanan Bitlis İline ait rüzgâr hızı dağılım haritası Şekil 5'te verilmiştir [25]. 


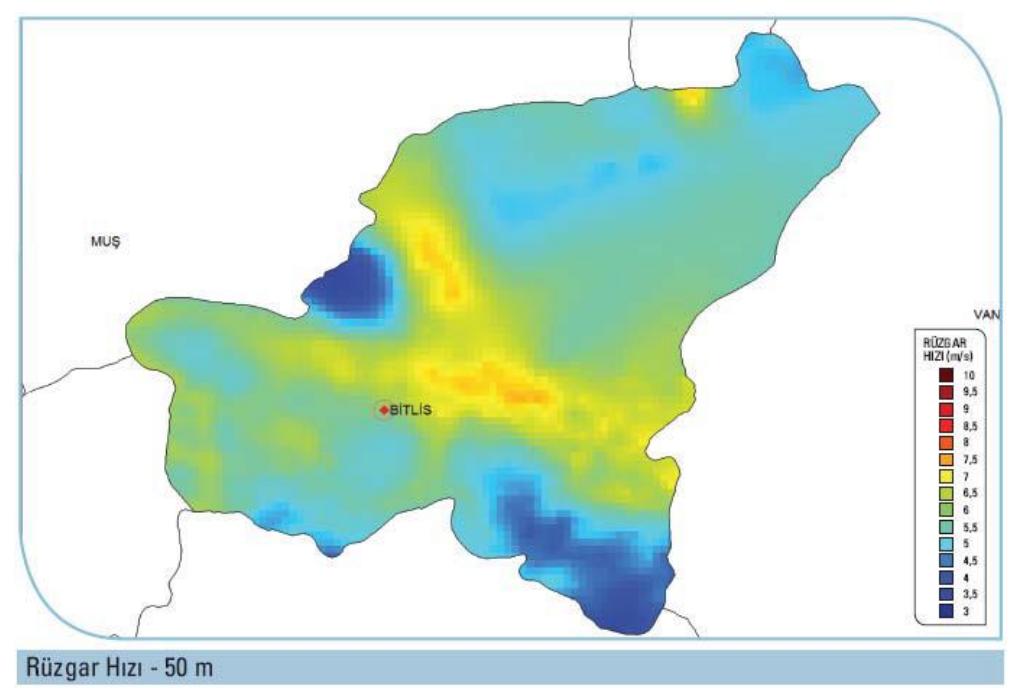

Şekil 5. Bitlis iline ait rüzgâr hız dağılımı

Oluşan hava akımının kinetik enerjisini bir türbin yardımı ile elektrik enerjisine dönüştüren sistemlere Rüzgâr Enerji Sistemleri(RES) denir. Rüzgâr türbinleri, hareket halindeki havanın kinetik enerjisini önce mekanik enerjiye daha sonra elektrik enerjisine dönüştürür. Rüzgâr türbinlerinin teorik çalışmalarda kullanılması için oluşturulan benzetimler matematiksel yapı temeli üzerine kuruludur. $\mathrm{Bu}$ nedenledir ki rüzgâr türbini tasarlanırken matematiksel eşitliklerin iyi analiz edilmesi gerekmektedir. Bir rüzgâr türbininden elde edilecek güç eşitlik (5) ile ifade edilir:

$$
P_{m}=\frac{1}{2} \rho A V^{3} C_{p}(\lambda, \beta)
$$

Burada $\rho$ havanın özgül yoğunluğunu $\left(\mathrm{kg} / \mathrm{m}^{3}\right), A$ kanat süpürme alanını $\left(\mathrm{m}^{2}\right), V$ rüzgâr hızını $(\mathrm{m} / \mathrm{s}), \mathrm{C}_{\mathrm{p}}$ güç dönüşüm katsayısını, $\lambda$ kanat uç-hız oranını, $\beta$ ise radyan cinsinden kanatların eğim açısını ifade etmektedir.

Bu eşitlik detaylandırılacak olursa;

$$
C_{p}(\lambda, \beta)=\mathrm{c}_{1}\left(\frac{c_{2}}{\lambda_{i}}-c_{3} \beta-c_{4}\right) e^{\frac{-c_{5}}{\lambda_{i}}}+c_{6} \lambda
$$

Eşitlik (6)'da tanımlanan c sabitleri için; $\mathrm{c}_{1}=0.5176, \mathrm{c}_{2}=116, \mathrm{c}_{3}=0.4, \mathrm{c}_{4}=5, \mathrm{c}_{5}=21 \mathrm{ve}_{6}=$ 0.0068 değerleri kullanılır. Eşitlikteki diğer parametreler için

$\frac{1}{\lambda_{i}}=\frac{1}{\lambda+0,08 \beta}-\frac{0,035}{\beta^{3}+1}$

$$
\lambda=\frac{\omega r}{V}
$$

$A=\pi r^{2}$

ifadeleri elde edilir. Burada $\omega$ türbinin dönüş hızı ( $\mathrm{rad} / \mathrm{s})$ ve $\mathrm{r}$ de türbin kanadının yarıçapıdır $(\mathrm{m})$. Bir türbin için,

$$
T_{m}=\frac{P_{m}}{\omega}
$$


eşitliği bilindiğinden türbin rotorundan elde edilecek mekanik tork ifadesi (9) eşitliği ile verilmektedir [23].

$T_{m}=\frac{1}{2 \omega} \rho \pi r^{5} C_{p}(\beta, \lambda) V^{3}$

Sistemin diğer enerji kaynağ olan RES bileşenine ait türbin $500 \mathrm{~W}$ anma gücüne sahip olup, 12 $\mathrm{m} / \mathrm{s}$ anma rüzgâr hızında üç fazlı 24V AC gerilim üretmektedir.

\section{Bulgular ve Tartışma}

Yenilenebilir enerji kaynaklarının yaygın kullanılmaya başlanması bu tip sistemlerin farklı uygulamalarının ortaya çıkmasına neden olmuştur. Makine sanayiinde yaygınlaşan depolama birimine sahip olmayan teknolojinin; azaltılmış bakım, artırılmış dayanıklılık, güvenilirlik ve düşük işletme maliyeti sağladığı kanıtlanmıştır. Bitlis ve çevresinde yaygın olarak tarımsal sulama yapıldığı ve tarımsal sulama alanda yapılan ARM'li çalışmalar da göz önünde bulundurulduğunda, bu çalışmada, enerji depolama ünitesiz sistem tasarlanıp, depolamalı sistemler ile performans açısından karşılaştırma yapılması amaçlanmıştır [26]. Bu kapsamda çeşitli çalışma koşulları için ölçüm verileri alınarak daha kolay karşılaştırma yapılması açısından grafik olarak sunulmuştur. Tasarlanan sistem bileşenlerinden hibrit enerji sistemi Şekil 6'da, ARM'li uygulama sistemi ise Şekil 7'de gösterilmiştir.
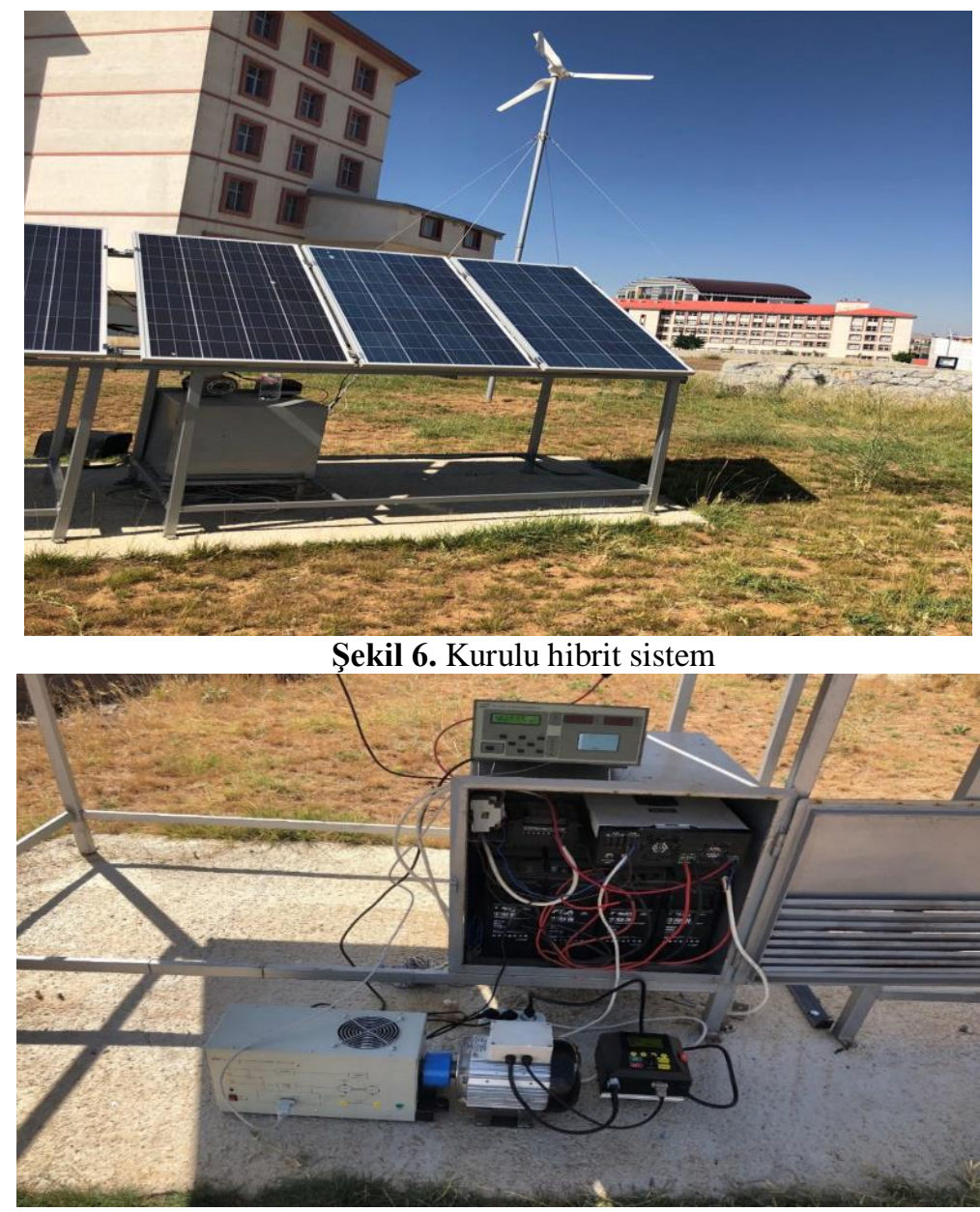

Şekil 7. Deneysel uygulama sistemi

Bu çalışmada ARM'nin yüksüz ve yük altında, farklı iklim koşulları için hız performans analizi yapılmıştır. Şekil 8'de hibrit sistem tarafından beslenen enerji depolama ünitesi ile enerjilendirilen, yüksüz durumdaki ARM'nin devir hızı grafiği gösterilmiştir. 


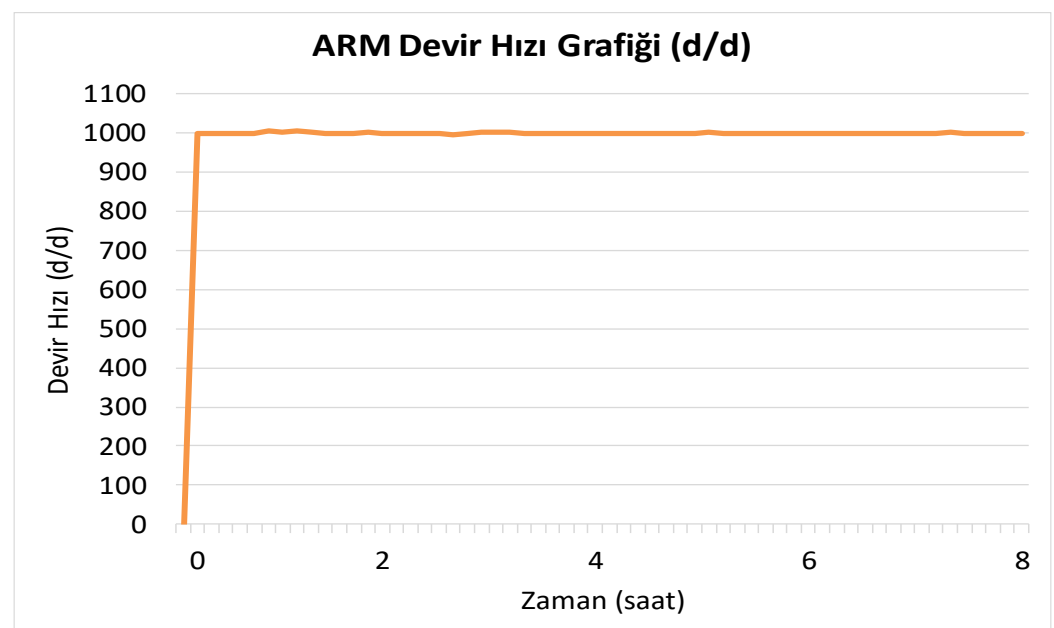

Şekil 8. Tam dolu depolama üniteli beslemede ARM devir hızı grafiği

Grafikten anlaşılacağı üzere motor depolama ünitesinden beslendiğinde hız açısından kararlı bir karaktere sahip olmaktadır. Sistemin enerji üretim sistemleri devreden çıkarılarak depolama ünitesinin beslemesi kesildiğinde depolama ünitesi kapasitesi ile motor hızı değişimi sırasıyla Şekil 9 ve Şekil 10'da karşılaştırmalı olarak verilmiştir.

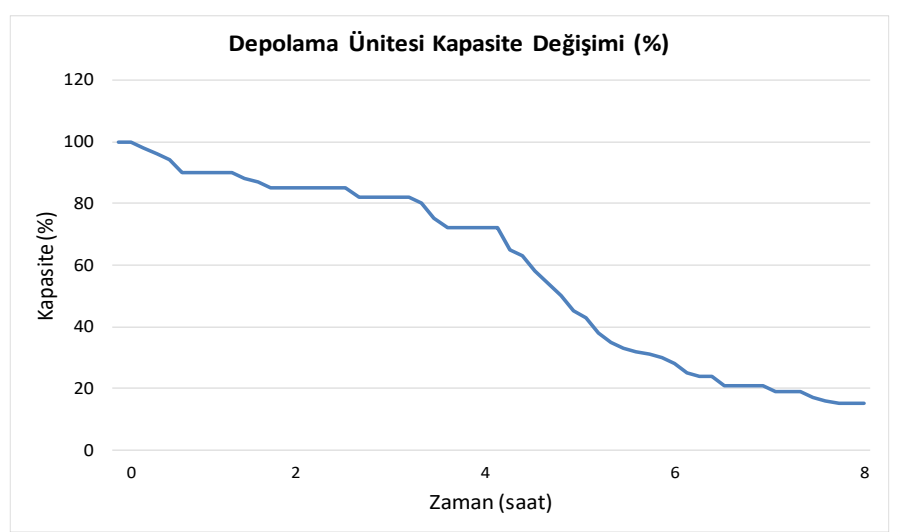

Şekil 9. Depolama ünitesi kapasite değişimi

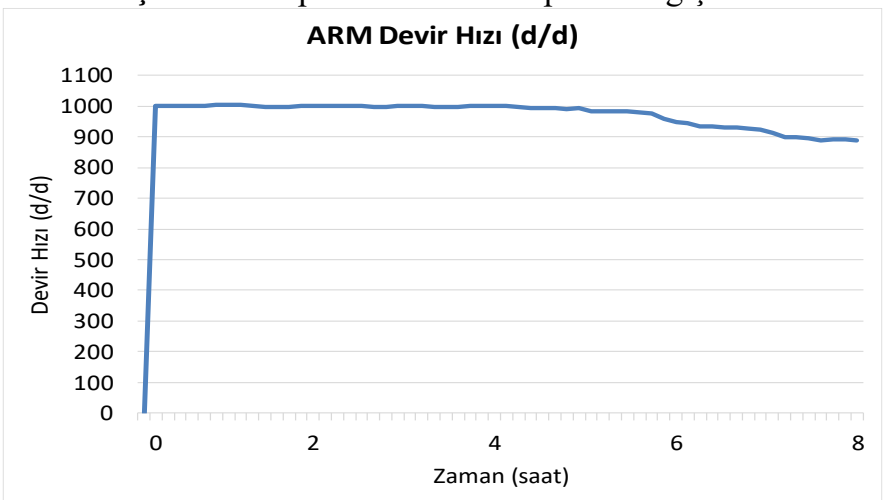

Şekil 10. Depolama ünitesi kapasitesine göre ARM devir hızı grafiği

Grafikler bağlantılı olarak incelendiğinde depolama kapasitesinin yaklaşık \%50 olduğu andan sonra motor hızının düşüş karakteri göstermeye başladığı anlaşılmaktadır. Bu durum depolama ünitesinin seçiminde detaylı analiz yapılmasının önemini bir kez daha ortaya çıkarmaktadır.

$\mathrm{Bu}$ çalışmanın temel amacı olan depolamasız sistem performansının incelenmesi için, hibrit sistem depolama biriminden ayrılmış ve analiz yapılmıştır. Şekil 11'de tam ışııım ve tam rüzgâr durumunda depolamasız sistemin farklı yükleme koşullarında devir hızı-zaman grafiği gösterilmektedir. 


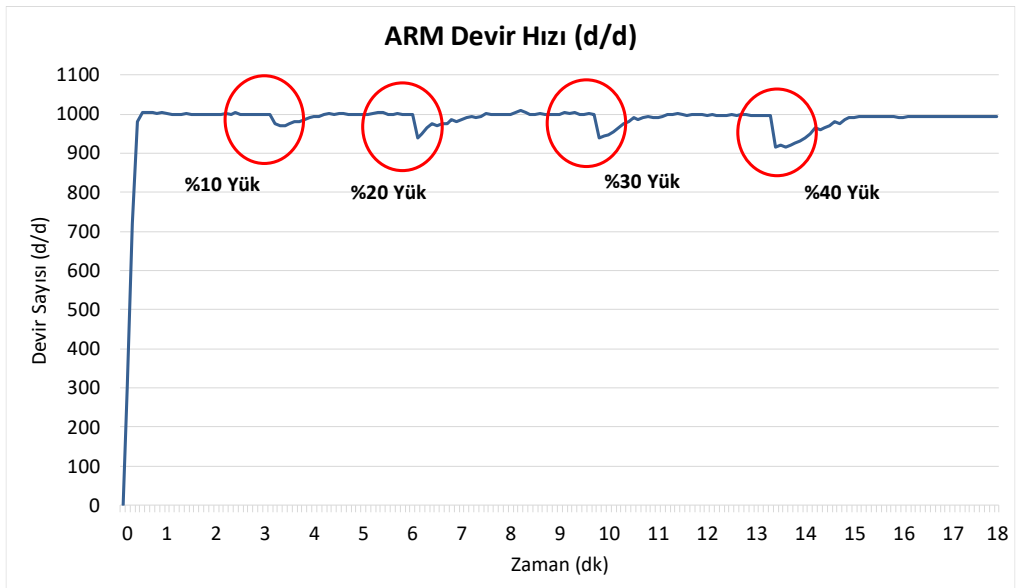

Şekil 11. Tam ışınım ve tam rüzgâr durumunda devir hızı değişimi

Şekil 11'de verilen grafiğin oluşturulmasında kullanılan ışınım ve rüzgâr verileri, sırasıyla evirici ve rüzgâr şarj kontrol biriminden alınan değerlerden elde edilmiştir. Buna göre, türbin çıkışındaki gerilim değeri $24 \mathrm{~V}$ olarak ölçülmüş, türbin yapısı gereği bu değer $12 \mathrm{~m} / \mathrm{s}$ rüzgâr hızından elde edilebileceği için tam rüzgâr durumu olarak kabul edilmiştir. Benzer şekilde fotovoltaik panel çıkışlarından, panel özelliklerine göre açık devre gerilim değeri olan $18 \mathrm{~V}$ değeri ölçülmüş, dolayısıyla bu durum da tam ışıma durumu olarak değerlendirilmiştir.

Farklı çalışma koşulları için yapılan analizlerdeki oransal ışıma ve rüzgâr değerleri de yine türbin şarj kontrolör ve panel çıkış değerlerinden elde edilmiştir. Rüzgâr değerinin elde edilmesinde herhangi bir dış müdahalede bulunulmamış, tamamen sistemin kurulu bulunduğu bölgenin meteorolojik şartlarından yararlanılmıştır. Bununla birlikte 1şıma değeri panellerin kontrollü biçimde karartılması ile ayarlanmıştır. Sistem bütünlüğünün bozulmaması için devreden panel çıkarma yerine karartma yapma yolu izlenmiştir.

Motor $1000 \mathrm{dev} / \mathrm{dk}$ hızına ulaştıktan sonra \%10 oranında yüklenmiş ve hızda ilk anda düşüş gözlense de motor hızını korumuş ve yeniden $1000 \mathrm{dev} / \mathrm{dk}$ hızına ulaşmıştır. Kademe kademe arttırılan yüke rağmen motor tam ışınım ve tam rüzgâr durumunda \%40 yükte hızını korumuştur. Bölgemize ait güneş ve rüzgâr haritaları göz önüne alınarak Bitlis ilinde kurulacak sistemden istenen verimin alınacağı aşikârdır. Değişken rüzgâr ve \%75 1şınım durum grafiği Şekil 12'de verilmiştir. Rüzgâr değişimi, şarj kontrol biriminden alınan verilere göre $7 \mathrm{~m} / \mathrm{s}$ ile $11 \mathrm{~m} / \mathrm{s}$ aralığındadır.

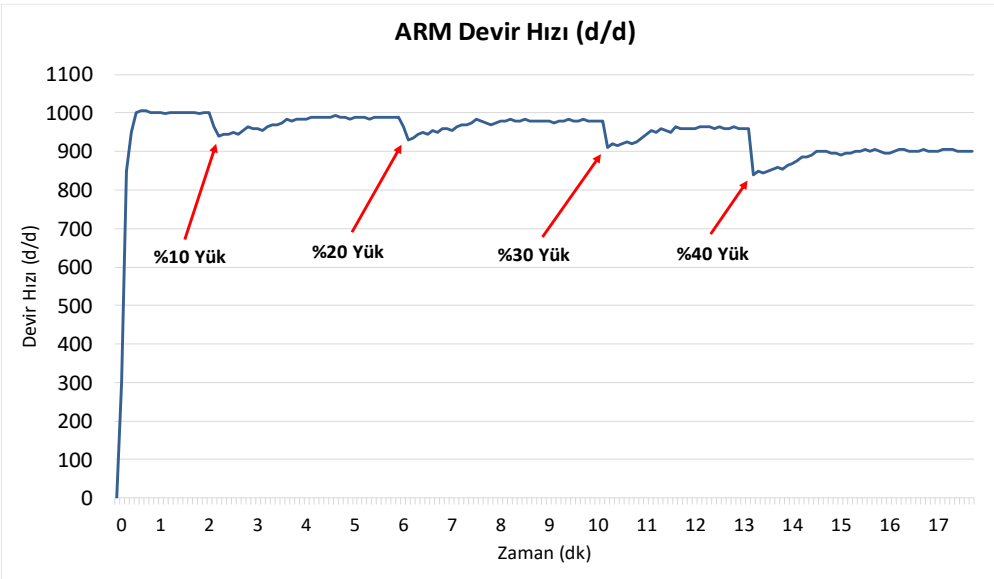

Şekil 12. Değişken rüzgâr ve \%75 1şınım durumunda devir hızı değişimi

Şekil 12'de verilen grafikten görüleceği üzere, \%10 oranında yüklenen motorun tam 1şınım ve rüzgâr durumuna göre toparlanma süresi uzasa da istenen performans sağlanmıştır. Yük kademe kademe $\% 10$ oranında arttırılarak hızdaki değişim gözlenmiştir. Son olarak \%40 oranındaki yük durumunda motor hızında yalnızca \%10 oranında düşüş gözlenmektedir. Rüzgârsız ve \%60 1şınım durumunda devir hızı değişimi Şekil 13 'te gösterilmiş̧ir. Rüzgârsız durum türbin kanatlarının dönmediği durumdur. 


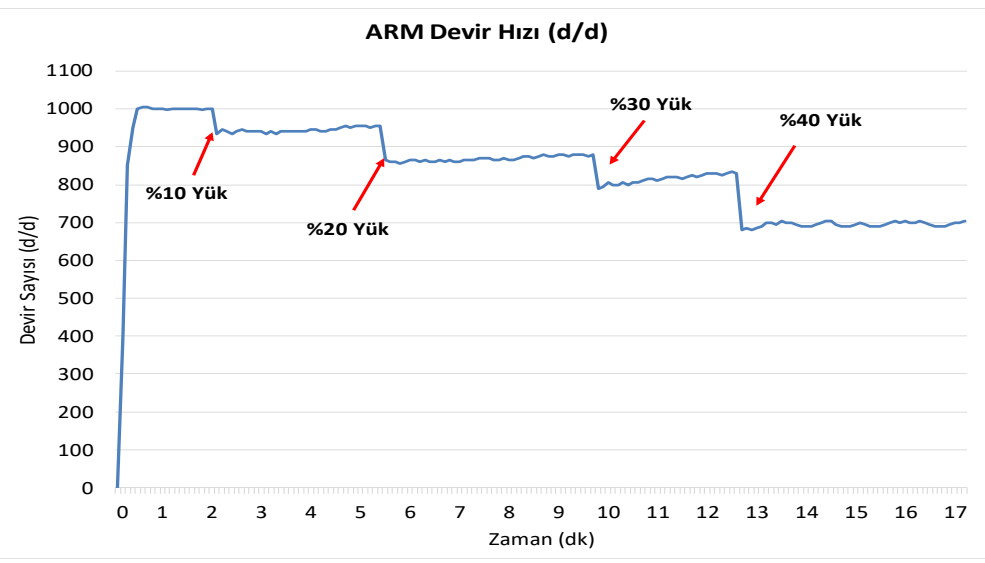

Şekil 13. Rüzgârsız ve \%60 1şııım durumunda devir hızı değişimi

Rüzgâr türbininin devreden çıkarıldığı ve \%60 1şınım ile yüksüz durumda motor $1000 \mathrm{dev} / \mathrm{dk}$ hızına ulaşmıştır. \%40 oranındaki yük durumunda motor hızı küçük salınımlar göstermekle birlikte 700 dev/dk da sabitlenmiştir. Depolama ünitesiz sistemde yaşanan hız düşüşlerini önlemek amacıyla; sisteme entegre edilecek akıllı bir yük kontrol sistemi; devir sayısı düşüşlerine ya da 1şınıma bağlı kontrollü yük atma işlemi gerçekleştirilerek hız optimizasyonu sağlanabilir.

\section{Sonuç ve Öneriler}

$\mathrm{Bu}$ çalışmada yenilenebilir enerji kaynaklarıyla beslenen ARM'nin depolama üniteli ve depolama ünitesiz analizi yapılmıştır. Tam ışınım ve tam rüzgâr durumu ile tam dolu depolama üniteli durum karşılaştırıldığında, motorun her iki sistem için neredeyse aynı performansı sahip olduğu sonucuna ulaşılmıştır. Bu durum, maliyet açısından depolama ünitesiz sistemin daha avantajlı olduğunu göstermektedir. Değişken rüzgâr ve \%75 1şınım durumu için grafik incelendiğinde sistem \%40 yüklü olmasına rağmen hızında yalnızca \%10 düşüş yaşanmıştır. Elde edilen deneysel verilere göre; YEK ile beslenen ARM'nin tarımsal sulama açısından uygunluğu kanıtlanmıştır. Sistemde depolama birimi bulunmamasının azaltılmış bakım, artırılmış dayanıklılık, güvenilirlik ve düşük işletme maliyeti gibi avantajlar sağladığını söylemek mümkündür. Ancak bölgemizdeki mevsim şartları, güneşlenme süresi ve rüzgâr haritası göz önünde bulundurulduğunda depolama ünitesiz sistem için verimi arttıracak, yüklenme durumlarındaki hız düşüşlerini optimize edecek akıllı sistemler üzerinde çalışılması gerekmektedir.

\section{Teşekkür}

Bitlis Eren Üniversitesi Bilimsel Araştırma Projeleri Birimi'ne, BEBAP 2017.09 ve BEBAP 2018.06 numaralı projeler kapsamında verdikleri desteklerden dolayı teşekkür ederiz.

\section{Kaynaklar}

[1] Çetin E., Ahmet Y., Öner Y., Öztürk H.K. 2007. Aydınlatmada Fotovoltaik-Hidrojen Hibrit Enerji Kaynağı Kullanımı. IV. Ulusal Aydınlatma Sempozyumu, 13-15 Aralık 2007, İzmir.

[2] Fulzele J.B., Daigavane M.B. 2018. Design and Optimization of Hybrid PV-Wind Renewable Energy System. Materials Today: Proceedings, 5: 810-818.

[3] Sigarchian S.G., Malmquist A., Fransson T. 2014. Modeling and control strategy of a hybrid PV/Wind/Engine/Battery system to provide electricity and drinkable water for remote applications. Energy Procedia, 57: 1401-1410.

[4] Engin M. 2013. Sizing and Simulation of PV-Wind Hybrid Power System. International Journal of Photoenergy, 2013: 1-10.

[5] Miller T.J.E. 1989. Brushless Permanent Magnet and Reluctance Motor Drives, Clarendon Press, Oxford. 
[6] Ishikawa T., Dohmeki H. 2012. The fundamental design technique of switched reluctance motors, and comparison with PMSM. XX ${ }^{\text {th }}$ International Conference on Electrical Machines, 2-5 Sept. 2012, Marseille.

[7] Tseng G.M., Jhong K.J., Tsai M.C., Huang P.W., Lee W.H. 2016. Application of Additive Manufacturing for Low Torque Ripple of 6/4 Switched Reluctance Motor. 19th International Conference on Electrical Machines and Systems (ICEMS), 13-16 Nov. 2016, Chiba.

[8] Indragandhi V., Selvamathi R., Arunkumari T. 2017. Speed Control of a Switched Reluctance Motor Using PID Controller for PV Based Water Pumping Applications. International Conference on Innovations in Power and Advanced Computing Technologies, 21-22 April 2017, Vellore.

[9] Ronanki D., Parthiban P. 2012. PV-Battery Powered Direct Torque Controlled Switched Reluctance Motor Drive. 2012 Asia-Pacific Power and Energy Engineering Conference, 27-29 March 2012, Shanghai.

[10] Singh B, Mishra A.K., Kumar, R. 2015. Buck-Boost Converter Fed SRM Drive for Solar PV Array Based Water Pumping. IEEE IAS Joint Industrial and Commercial Power Systems / Petroleum and Chemical Industry Conference (ICPSPCIC), 19-21 Nov. 2015, Hyderabad.

[11] Efe S.B., Demir D. 2018. Analysis of PV Supplied SRM for Different Operating Conditions. $7^{\text {th }}$ International Conference on Advanced Technologies, April 28- May 01 2018, Antalya.

[12] Miller T.J.E. 1993. Switched Reluctance Motors and Their Control, Magna Physics Publishing and Clarendon Press, Oxford.

[13] Llibre J.-F., Martinez N., Leprince P., Nogarede B. 2013. Analysis and Modeling of LinearSwitched Reluctance for Medical Application. Actuators, 2 (2): 27-44.

[14] Rasakannu J., Chinnagounder C. 2016. Design and implementation of small power switched reluctance generator-based wind energy conversion system. Turkish Journal of Electrical Engineering and Computer Sciences, 24 (4): 3228-3239.

[15] Kentli F., Çalik, H. 2011. Matlab-simulink modelling of 6/4 SRM with static data produced using finite element method. Acta Polytechnica Hungarica, 8 (6): 23-42.

[16] Efe S.B., Kocaman B., Aktaş Demir D. 2018. Operational Analysis of a Switched Reluctance Motor Fed by PV System. International Conference on Electrical and Electronics Engineering, 910 August 2018, Amsterdam.

[17] Mishra A.K., Singh B. 2016. A Single Stage Solar PV Array Based Water Pumping System Using SRM Drive. 2016 IEEE Industry Applications Society Annual Meeting, 2-6 Oct. 2016, Portland.

[18] Dursun M., Saygin A. 2006. Güneş Enerjisi ile Çalışan Bir Sulama Sistemi için Boost Konvertörlü Anahtarlamalı Relüktans Motor Sürücüsü. Erciyes Üniversitesi Fen Bilimleri Enstitüsü Dergisi, $22(1-2): 57-65$.

[19] Çelik A., Kılıç I.M.K. 2008. Fotovoltaik Sistem Eğitimi İçin Bir Simulink Araç Kutusu Tasarım ve Uygulamas1. e-Journal of New World Sciences Academy, 3 (3) :499-514.

[20] Cengiz M.S., Mamiş M.S. 2015. Price-efficiency relationship for photovoltaic systems on a global basis. International Journal of Photoenergy, 2015: 1-12.

[21] Y1lmaz M., Kentli, F. 2014. Increasing of Electrical Energy with Solar Tracking System at the Region which Has Turkey's Most Solar Energy Potential. Journal of Clean Energy Technologies, 3 (4): $287-290$.

[22] Kentli F., Yilmaz, M. 2015. Mathematical modelling of two-axis photovoltaic system with improved efficiency. Elektronika Ir Elektrotechnika, 21 (4): 40-43.

[23] Efe S.B. 2014. Mikro Şebekelerde Güç Akış Analizi. Doktora Tezi, Fırat Üniversitesi Fen Bilimleri Enstitüsü, 103s, Elazığ.

[24] Güneş Enerjisi. http://www.yegm.gov.tr/ (Erişim Tarihi: 05.02.2019)

[25] Rüzgar Enerjisi. http://www.yegm.gov.tr/ (Erişim Tarihi: 05.02.2019).

[26] Demir Aktaş D. 2018. Yenilenebilir Enerji Kaynaklarıyla Beslenen Anahtarlamalı Relüktans Motorun Performans Analizi. Yüksek Lisans Tezi, Bitlis Eren Üniversitesi Fen Bilimleri Enstitüsü, 46s, Bitlis. 